\title{
Evaluation of a Tier 3 Specialist Weight Management Service for morbidly obese patients
}

\author{
A.R. Kininmonth and J. Bradbury \\ School of Applied Sciences, University of Huddersfield, Huddersfield HD1 3DH
}

Rates of obesity have increased rapidly over the past 25 years, with $24.7 \%$ of UK adults obese $\left(\mathrm{BMI} \geqslant 30 \mathrm{~kg} / \mathrm{m}^{2}\right)^{(1)}$. Prevalence is higher in Wakefield with $28.5 \%$ of adults classified as obese ${ }^{(2)}$. Public Health England identifies 'tackling obesity' as a main priority for the next 5 years $^{(3)}$; in response, local authorities commission dedicated Weight Management Services (WMS), which offer support and treatment for obese individuals. WMS that focus on behaviour change, nutritional education, and exercise can be effective at helping patients achieve clinically significant weight loss $(\geqslant 5 \% \text { baseline weight })^{(4,5)}$. However, there is currently limited published evidence to show effective WMS for individuals with co-morbidities and BMI $\geqslant 45 \mathrm{~kg} / \mathrm{m}^{2}$. The aim of this study was to assess the effectiveness of Wakefield's Tier 3 Specialist Weight Management Service (SWMS) at helping patients achieve $\geqslant 5 \%$ weight loss.

The service was evaluated using the National Obesity Observatory Standard Evaluation Framework ${ }^{(6)}$. Patients were adults referred to and commencing on the SWMS between 2014 and 2015. The inclusion criteria were adults living in Wakefield aged $\geqslant 16$ yrs with a BMI $\geqslant 45 \mathrm{~kg} / \mathrm{m}^{2}$ or BMI $>30 \mathrm{~kg} / \mathrm{m}^{2}$ with complex co-morbidities. Data were analysed on an intention-to-treat basis and it was assumed that patients who did not complete the 12 weeks maintained baseline weight. Patient weight and height at week 1 (baseline), week 12 (end) and 6 months (follow up) were used to calculate BMI. Changes in weight at 12 weeks and 6 months were expressed as a percentage of baseline weight. Weight loss $\geqslant 5 \%$ of baseline weight was defined as a successful weight loss outcome.

In total, 280 patients commenced [188 (67\%) females; 92 (33\%) males] and 191 (68\%) [125 (65\%) females; 66 (35\%) males] completed the intervention, representing an attrition rate of $32 \%$. Weight was significantly reduced at 12 weeks compared with baseline (p $<0.001$ ) (see table). Fifty-four percent of patients who completed $(\mathrm{n}=191)$ the 12 week intervention lost weight, although only $16 \%$ lost $\geqslant 5 \%$ of initial body weight; $14 \%$ gained weight. Weight gains ranged between 0.1 to $10 \mathrm{~kg}$ at 12 weeks, for these patient's weight was significantly greater at 12 weeks compared with baseline $(\mathrm{p}<0.001)$. Patients who attended group sessions had significantly greater reductions in weight compared with patients attending one-to-one sessions $(p=0.04)$.

\begin{tabular}{|c|c|c|c|c|c|c|}
\hline & \multicolumn{2}{|c|}{ Baseline } & \multicolumn{2}{|c|}{12 weeks } & \multicolumn{2}{|c|}{6 months } \\
\hline & Weight (kg) & BMI $\left(\mathrm{kg} / \mathrm{m}^{2}\right)$ & Weight (kg) & BMI $\left(\mathrm{kg} / \mathrm{m}^{2}\right)$ & Weight (kg) & BMI $\left(\mathrm{kg} / \mathrm{m}^{2}\right)$ \\
\hline Mean (SD) & $138.9(27 \cdot 2)$ & $49.4(7.4)$ & $136.4(27.4)$ & $48.6(8 \cdot 2)$ & $136 \cdot 3(27 \cdot 5)$ & $48 \cdot 5(7 \cdot 5)$ \\
\hline Median (IQR) & $132.4(30 \cdot 3)$ & $48 \cdot 3(7 \cdot 2)$ & $130.6(29.7)$ & $47.4(7.7)$ & $130 \cdot 6(30 \cdot 3)$ & $47 \cdot 3(7 \cdot 8)$ \\
\hline Minimum & $84 \cdot 4$ & $34 \cdot 2$ & $86 \cdot 0$ & 33.6 & 86.0 & $32 \cdot 6$ \\
\hline Maximum & $265 \cdot 6$ & $78 \cdot 5$ & $260 \cdot 8$ & $81 \cdot 9$ & $260 \cdot 8$ & $81 \cdot 9$ \\
\hline
\end{tabular}

The SWMS was effective at helping some patients lose weight. However, improvements to the service are required to increase the number that complete the programme, and who achieve a clinically significant weight loss outcome.

1. Eastwood P. (2014). Statistics on Obesity, Physical Activity and Diet: England 2014. Lifestyle statistics team, Health and Social Care Information Centre. ISBN 978-1-78386-065-4

2. Wakefield Observatory. (2015). Wakefield Joint Strategic Needs Assessment. Healthy Living: Obesity. Retrieved from: http://www.wakefieldjsna.co. uk/promotion-prevention/obesity/ (accessed Feb 2016)

3. Public Health England. (2014). From evidence into action: opportunities to protect and improve the nation's health. https://www.gov.uk/government/ uploads/system/uploads/attachment_data/file/366852/PHE_Priorities.pdf (accessed Jan 2016)

4. Wirth A., Wabitsch M., \& Hauner H. (2014). The Prevention and Treatment of Obesity. Dtsch Ärztebl Int. 111, 705-713.

5. Waine C. (2002). Obesity and Weight Management in Primary Care. Oxford: Blackwell Publishing.

6. National Obesity Observatory (2009). Standard Evaluation Framework for weight management interventions. http://www.noo.org.uk/uploads/ doc721_2_noo_SEF\%20FINAL300309.pdf (accessed Mar 2016) 